\title{
Finite Element Analysis of Interactions between two cracks in FGM notched Plate under Mechanical Loading
}

\author{
Aboubakar Seddik Bouchikhi, Abdelkader Lousdad, Khalfi Yassine, Nasser Eddine Bouida, \\ Sadek Gouasmi, Abdelkader Megueni \\ Department of Mechanics, BP 89, Cité Ben M'bidi - Sidi Bel Abbes (22000), University of Sidi Bel Abbès, Sidi Bel Abbes, \\ Algeria \\ bouida24@gmail.com,as_boucbikbi@univ-sba.dz.
}

\begin{abstract}
The investigation of multiple crack interactions in fracture mechanics is important to predict the safety and reliability of structures. This paper introduces a 2D numerical investigation used to calculate the J-integral of the main crack behavior emanating from a semicircular notch and double semicircular notch and its interaction with another crack which may occur in various positions in titanium / titanium boride functionally graded material (TiB/Ti FGM) plate subjected to tensile mechanical load. Young's modulus of the functionally graded material plate varies along the specimen width (notch radius direction r-FGM) with exponential-law (E-FGM) function. Further, the Poisson's ratio is taken as a constant in normal direction. For this purpose the variations of the material properties are applied at the integration points and at the nodes by implementing a subroutine USDFLD in the ABAQUS software. The variation of the J-integral according to the position, the length, and the angle of rotation of cracks are examined; also the effect of different parameters for double notch FGM plate is investigated as well as the effect of band of FGM within the ceramic plate to reduce Jintegral. According to the numerical analysis, all parameters above played an important role in determining the J-integral.
\end{abstract}

KEYWORDS. Functionally graded material (FGM); Finite element method (FEM); Crack; J Integral; Mode I; Interaction.

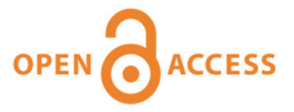

Citation: Bouida, N., Bouchikhi, A.S., Lousdad, A., Gouasmi, S., Megueni, A., Finite Element Analysis of Interactions of between two cracks in FGM notched Plate under Mechanical Loading, Frattura ed Integrità Strutturale, 48 (2019) 174-192.

Received: 29.12 .2018

Accepted: 17.02.2019

Published: 01.04.2019

Copyright: (C) 2019 This is an open access article under the terms of the CC-BY 4.0, which permits unrestricted use, distribution, and reproduction in any medium, provided the original author and source are credited.

\section{INTRODUCTION}

he formations of cracks are strongly depending on the type of materials, loading, environmental aggression and design condition of mechanical components. In general, crack grows perpendicularly to the axis of loading. However under circumstances, a crack also propagates obliquely especially as a result of hydrogen induced cold crack after the metal welding. In this case, most cracks appeared not in a single crack but in the form of multiple cracks. Tremendous amount of works can be found in analyzing the growth crack in open literature [1-3]. For examples Matsumto et al. [1] evaluated the stress intensity factor of growth crack along two different materials using an interaction 
energy release rate and boundary element method. In order to indicate the reliability of their method, some numerical models are used and compared. The present method capable to produce more accurate results with a coarse mesh than the method based on the displacement extrapolation which is based on the boundary element method.

Hammond and Fawaz [2] reviewed stress intensity factors of various size single edge-cracked tension specimens. Finite element method is used to calculate the stress intensity factors for wide ranges of crack and sample geometries. Comparison is also performed between the existing and their results generally satisfactory correlation and large differences about $12.7 \%$ is observed for short cracks in small plate aspect ratio.

Ismail et al. [3] investigated stress intensity factors of double edge cracks in large groove plate under mode I tension. They used finite element method to determine the stress intensity factor via domain integral method. It is found numerically that the stress intensity factor (SIFs) are strongly affected by the relative crack depth and the groove geometries. It is also found that the large groove is capable of reducing the SIFs in comparison with the circular notched due to lower stress concentration factors.

Several works discussed on the multiple normal cracks can also be found in [4-8]. For examples Yan and Miao [4] studied the interaction of multiple cracks in a rectangular plate using boundary element method. They reported that the boundary element method is simple yet accurate for determining the stress intensity factors of multiple crack problems. While, Yang and Soh [5] developed finite element method using complex potential and the conformal mapping technique to study the multiple crack problems. It is found that the method developed useful for modelling the crack interactions between many cracks and defects. Shu et al. [6] studied the problems of three cracks on both edges of finite width sheet under mode I loading. They modeled the multiple cracks using finite element method and due to symmetrical effect only half of model is developed. They found that when there are several cracks co-existed, the flexibility of the plate increased and the stress intensity factors at the crack tips decreased.

Ismail [7] studied the stress intensity factors of three parallel edge cracks under bending moments. Cracks are modeled using finite element method and different relative crack length and spacing between cracks are used. It is found that due to the presence of multiple crack edge cracks, the stress distribution is relaxed and therefore, the stress intensity factors for all cracks decreased and when the distance between the cracks is increased, interaction is seemed to be diminished and it is can be neglected especially for shallow cracks. The behavior of offset crack under mixed mode loading can also be found in [8]. In term of slanted cracks, several works are found such as [9-11]. Kuang and Chen [9] used a displacement extrapolation method to investigate the mixed mode crack problems under mode I loading. There are two important parameters are used such as crack length and size of element at the crack tip. However, when the crack is only slanted at limited angle, it is hard to understand the role of angles on the stress intensity factors.

Albinmousa et al. [10] provided solution of stress intensity factors for mixed mode I-II single edge notched tension specimen. Wide range of crack geometries and inclined angles are used and stress intensity factors are determined based on such parameters. Then, curve fitting is performed to simplify the stress intensity factors for prediction purposes. They found that their model can be used to predict the stress intensity factors very well.

Another study on the slanted crack can be found in [11-13]. However, this work focused on the 2D two dimensional cracks.

The present study consists in investigating the 2D simulation used to calculate the J-integral of the main crack behavior emanating from a semicircular notch and double semicircular notch and its interaction with another crack which may occur in various positions in (TiB/Ti) FGM plate under mode I. The J-integral is determined for various load applied. The cracked plate is joined by bonding a FGM layer to TiB plate on its double side. The determination of the gain on Jintegral by using FGM layer is highlighted.

The calculation of J integral of FGM's involves the direction of the radius of the notch in order to reduce the $\mathrm{J}$ integral. The graded finite elements are implemented in the FE software Abaqus 6.9 to verify the USDFLD used subroutine given in Appendix1.

\section{FRACTURE ANALYSIS}

The interaction integral

7 he interaction integral is derived from the path-independent J-integral [14] for two admissible states of a cracked elastic FGM. The standard J-integral is given by [14]:

$$
J=\lim _{\Gamma_{S} \rightarrow 0} \int_{\Gamma_{S}}\left(W \delta_{1 j}-\sigma_{i j} u_{i, 1}\right) n_{j} d \Gamma
$$


where $\mathrm{W}$ is the strain energy density, oij denotes the stress, ui denotes the displacements, and nj is the outward normal vector to the contour $\Gamma$, as shown in Fig. 1.

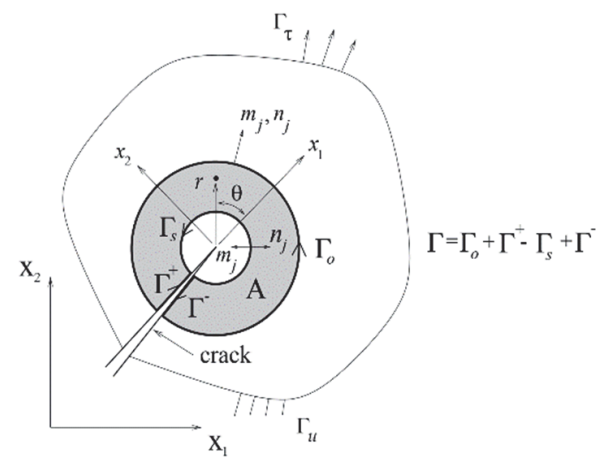

Figure 1: Schematic of a cracked body and notation.

\section{J-integral}

When a crack grows at the constant displacement the energy release rate (SERR) is determined by the following relationship [15]:

$$
G=-\frac{d U}{d A}
$$

G, $U$ and A respectively are the strain energy release rate, energy and area of the crack face. For the plane strain case the stress intensity factor (SIF) is achieved eq. 3. [15]:

$$
K_{I}^{2}=\frac{G E_{t i p}}{1-v^{2}}
$$

In which, Etip is Young's modulus at the crack tip. In the homogeneous materials, the SERR is equal to the J-integral, which is obtained through equation [14]:

$$
J=\int_{\Gamma}\left(W n_{1}-\sigma_{i j} \frac{\partial u_{j}}{\partial x_{1}}\right) d s
$$

where $\mathrm{ds} \mathrm{A}$ is the area inside the contour.

For $2 \mathrm{D}$ cracked plates $\Gamma$ is a favorite path begins from the lowest edge and ends at the highest edge of the crack.W, $\mathrm{u}_{\mathrm{i}}$, and $n_{j}$ are the SERR, displacement component and the component of the unit vector normal to the $\Gamma$ path respectively. Neglecting the body forces, crack face tractions (crack surface assumed to be traction free) and thermal strains, the Jintegral is path independent for homogeneous materials. For these materials, the SERR, G, and the J-integral are similar. Independent J-integral

For the nonhomogeneous case, the SERR in addition to strain is dependent on $\mathrm{x}(\mathrm{W}(\mathrm{x})=\mathrm{W}(\varepsilon(\mathrm{x})$, $\mathrm{x}))$. For this reason, to obtain the contour independent J-integral, an extra term needs to be subtracted from the classical J-integral as follows [14]:

$$
J=\int_{\Gamma}\left(W n_{1}-\sigma_{i j} \frac{\partial u_{j}}{\partial x_{1}}\right) d s-\int_{A} W_{, 1} q d A
$$

where $\mathrm{q}$ is the weight function chosen such that it has a value of unity at the crack tip the strain energy density. In which, $\Gamma$ is a favorite path begins from the lowest edge and ends at the highest edge of crack and $\mathrm{A}$ is the area surrounded by the contour. W,1 denotes partial differentiation of W with respect to the $\mathrm{x}$ variable. The J-integral gives null magnitude for a closed contour in the homogeneous and nonhomogeneous materials. 
Hence, in fracture problems, it is permanently independent of path as it was analytically proved by Honein and Herrmann [14]. Ignoring the crack surface tractions and thermal stresses, the FEM formulation of the independent contour integral J is constructed using the following discredited form as suggested by Li et al. [16]:

$$
J=\sum_{A} \sum_{p=1}^{N}\left\{\left[\left(\sigma_{i j} u_{i, 1}-W \delta_{1, i}\right) q_{, 1 q 1}\right] \operatorname{det} \frac{\partial x_{k}}{\partial \zeta_{1}}\right\} w_{p}
$$

where: $w_{p}$ is the weight function of the corresponding Gaussian integration points and W, 1 is partial differentiation of W with respect to $\mathrm{x}$ when the Young's modulus $\mathrm{E}$ is an explicit function of $\mathrm{x}(\mathrm{E}=\mathrm{E}(\mathrm{x}))$. For the specified material property variation, analytically drive of the expression is simple. Meanwhile, in the accolade, all of the quantities are considered at the integration points for any element with the opted contour. $\mathrm{N}$ is defined the number of integration points of element and $\mathrm{q} 1$ is a parameter, employed to simplify the calculation of a contour integral in the FEM. In overall, a nodal value of 0 or 1 is given to Q1, while $\mathrm{q} 1$ is defined by the following relation [16]:

$$
q_{1}=\sum_{i=1}^{4} N_{i} Q_{1 i}
$$

In which $N_{i}$ represents the interpolation functions.

\section{Finite element Analysis}

This section details the finite-element formulation of enriched crack tip elements for mode I fracture analyses of 2dimensional cracks in FGMs. Similar to many other studies in the literature, the form of material property gradient functions is selected to be exponential. For the FGM domain shown in Fig. 1 containing an inclined embedded crack, the modulus of elasticity varies according to:

$$
\begin{aligned}
& E(x)=E_{1} e^{\beta r} \\
& \beta=\frac{1}{b} \operatorname{Ln}\left(\frac{E_{1}}{E_{2}}\right)
\end{aligned}
$$

where $\beta$ is a material constant and $\mathrm{r}$ is the coordinate by which the material property changes along the notch radius ( $\mathrm{r}-$ FGM) [17, 18]. $\mathrm{h}$ is the thickness of the plate and $\mathrm{E}$ is the Young modulus, E1 is the Young modulus at $\mathrm{r}=\mathrm{R}$, E1 and E2 Young modulus for ceramic and metal respectively Tab. 1. Indicates the scale of length over variations of the properties for validation of the FE model.

\begin{tabular}{ccc}
\hline Materials & $\begin{array}{c}\text { Young's modulus } \\
(\mathrm{GPa})\end{array}$ & Poisson's ratio \\
$\mathrm{Ti}$ & $\mathrm{E} 1=110$ & $\mathrm{v} 1=0.34$ \\
$\mathrm{TiB}$ & $\mathrm{E} 2=375$ & $\mathrm{v} 2=0.14$ \\
\hline
\end{tabular}

Table 1: Material properties of Ti and TiB.

As shown in Fig 2, a cracked rectangular FGM plate (Ti-TiB) plate with a semicircular notch at side under uniform loading $\left(\sigma_{0}=100 \mathrm{MPa}\right)$ is numerically simulated in the ABAQUS commercial FEM code Version 6.9.126 [19].

The geometrical characteristics of the FGM plate are the width $\mathrm{W}=200 \mathrm{~mm}$; the length $\mathrm{H}=2 \mathrm{~W}=400 \mathrm{~mm}$. To analyze the fracture behavior, a crack of length (c) is supposed to be initiated at the notch root with radius (R).

\section{Meshing}

An unstructured triangular mesh is automatically generated by employing the advancing front method. The singular elements have to be constructed correctly to get a proper field of singularity around the crack tip as shown in Fig. 3.

The number of elements depends on the distributed nodes around the crack tip, which can be set by the user as shown in Fig. 4. 


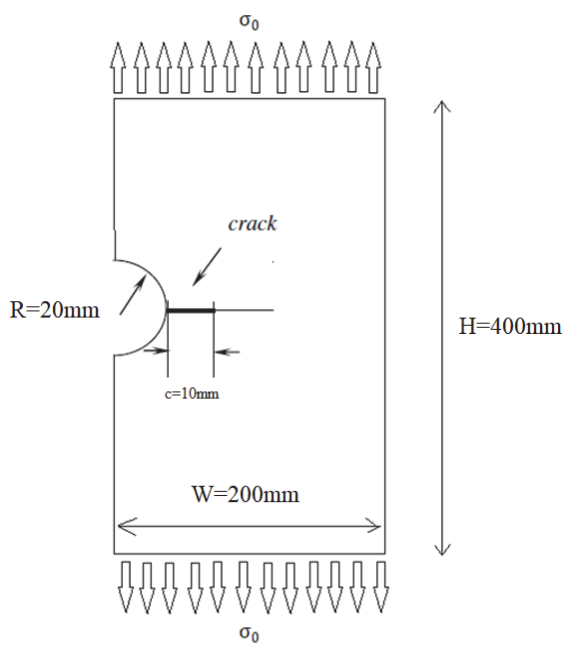

Figure 2: Geometrical model of notched FGM plate.
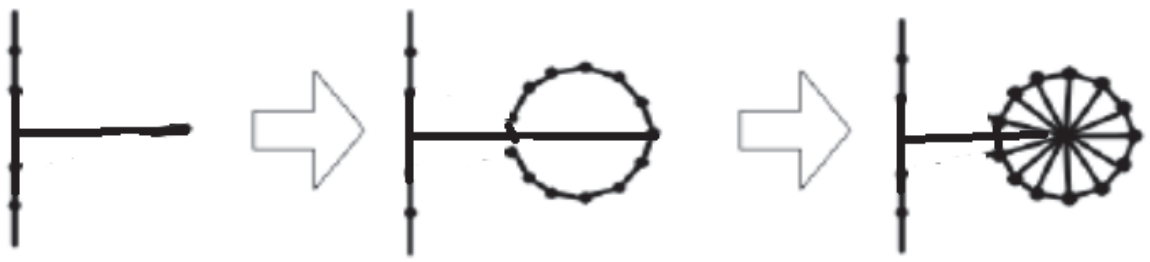

Figure 3: The cut and patch procedure of generating singular elements around a crack tip.

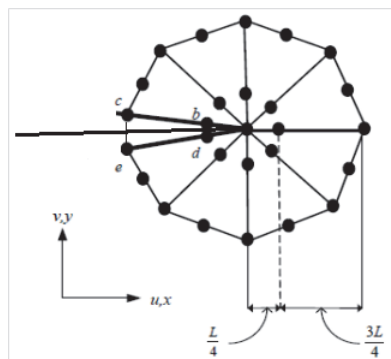

Figure 4: A typical arrangement of the natural triangle quarter-point elements around a crack tip.

In fact, the natural triangular quarter point elements are used [20] instead of the collapsed quadrilateral element, which is proposed by Barsoum [21]. The success of the adaptively in general depends to a large extent on the efficient coupling between the error estimator, refinement scheme and automatic mesh generator. The importance of these adaptive techniques in practical applications has led to a considerable research on fully automatic mesh generators that require only the specification of the boundary and mesh size distribution over the domain. Moreover, several comprehensive numerical tools have been developed to enhance the accuracy at the crack tip.

In this work, the unstructured triangle mesh is automatically generated by employing the advancing front method. Many researchers applied the FEM with remeshing to study the fracture propagation and its J-integral analysis ([22]; and [23]), though it is not an easy task. In contrast, it is almost impossible to automatically remesh finite elements of an arbitrarily growing crack [24]. One of the advantages of the advancing front method is that the new triangle element formation is coinstantaneous with new node generation, and this advantage makes it possible to control the shape and size of the element through the adjustment of the location of the node [25]. However, a lot of intersection checking between the new generated triangular elements and the existing elements must be computed in order to ensure that the triangular elements are valid. Accordingly, an observation was stated that the algorithm for the advancing front method has been shown to be robust in two-dimensional mesh generation of triangles and could be extended easily to generate quadrilaterals [26]. 
(a)

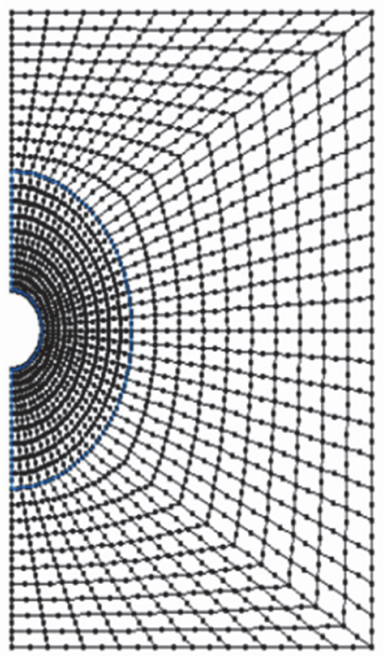

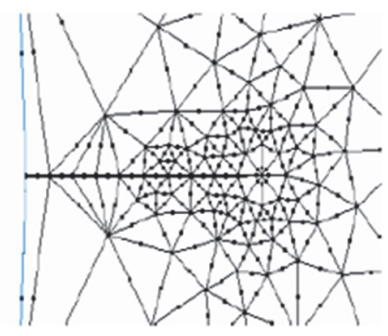

(b)

Figure 5: Meshing model of FGM plate. (a) of the plate and (b) near the crack tip.

\section{Adaptive Refinement Mesh}

In general, the smaller mesh size gives more accurate finite element approximate solution. However, reduction in the mesh size leads to greater computational effort. The adaptive mesh refinement is employed as the optimization scheme. This scheme bases on a posteriori error estimator which is obtained from the solution from the previous mesh. Basically, the success of the adaptively in overall is depends to a large extent on the efficient coupling between the error estimator, refinement scheme and automatic mesh generator. The importance of these adaptive techniques in practical applications has led to a considerable research on fully automatic mesh generators that require only the specification of the boundary and mesh size distribution over the domain.

\section{Convergence study}

The $\%$ error in J-integral obtained is plotted for various nodal discretizations in Fig.6. Notably, the FE method incorporates enrichment functions to model the crack-tip stress field [27]. The visibility and diffraction method involves modified weight functions around the crack tip. Their details are given in [28]. This plot shows that the present method decreases the $\%$ error in J-integral with increasing nodal density.

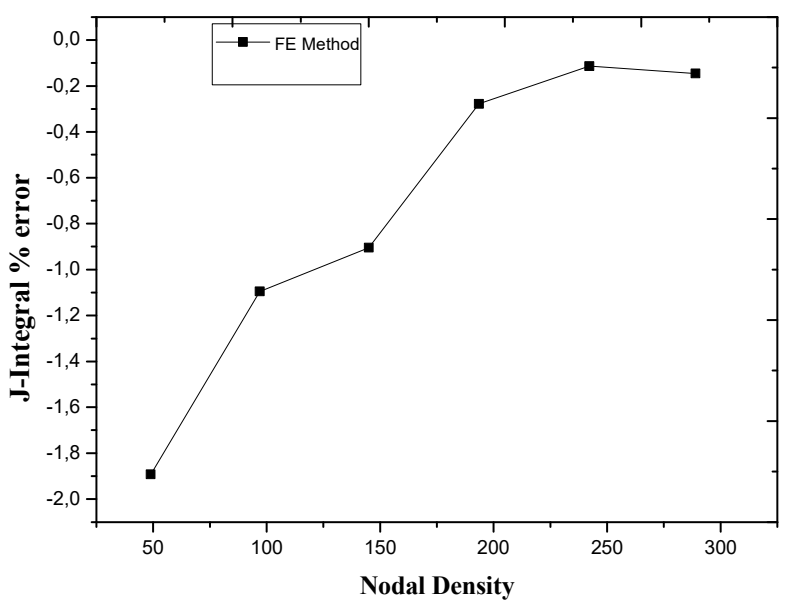

Figure 6: J-integral \% error with nodal density.

Fig. 7 shows the convergence of J-integral using a coarser nodal discretization of 66297, and the present FE method with various refinements in the region around the crack tip. It is observed that even with the usage of very low refinement, the 
J-integral \% error becomes less than $2 \%$. As the refinement increases, the error decreases and the result converges to the exact solution. This is advantageous especially for modeling the crack propagation through non-homogenous materials because this eliminates the need of enrichment functions.

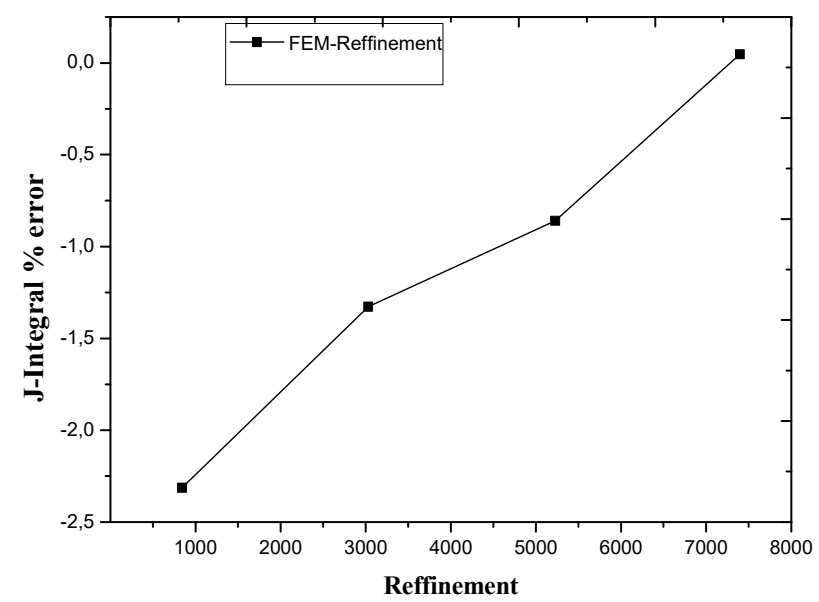

Figure 7: \% error in J-integral with refinement in the region around the crack tip, using the proposed method.

\section{RESULTS AND DisCUSSIONS}

$\mathrm{I}$

$\mathrm{n}$ this study the numerical calculation is based on FE using ABAQUS software. The direction of variation of the Young's modulus of the FGM is according to r-FGM $[17,18]$.

\section{Effect of crack-crack interaction according to their position on J-Integral}

In this Section, we studied the influence of the interaction between two cracks $\mathrm{AB}$ et $\mathrm{CD}$ according to their position on the J-Integral.
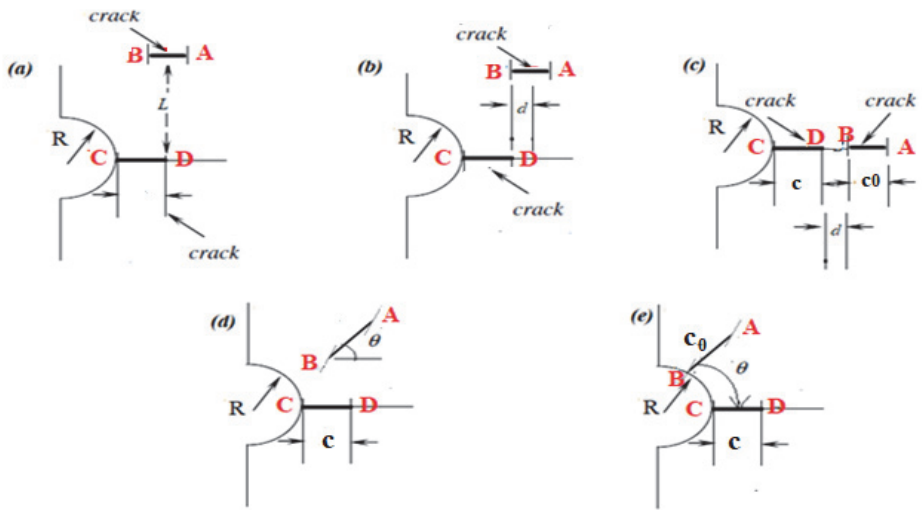

Figure 8: Interaction between two cracks for different positions.

Five different geometric configurations between two cracks $\mathrm{AB}$ and $\mathrm{CD}$ are studied, their interaction effects are analyzed and compared. Fig. 8 shows the details and designation of the geometrical shapes under consideration

(a) Two cracks (AB) and (CD) are parallel (it is perpendicular to the applied load), and the transversal interdistance $\boldsymbol{L}$ between is assumed variable of these two cracks.

(b) Two cracks (AB) and (CD) are parallel (it is perpendicular to the applied load), and the longitudinal interdistance $\boldsymbol{d}$ between is assumed variable of these two cracks. 
(c) Two cracks (AB) and (CD) collinear (ported by the same horizontal line and perpendicular to the applied load) and the longitudinal interdistance $\boldsymbol{d}$ between is assumed variable of these two cracks.

(d) Horizontal crack (CD) at notch with fixed orientation and an inclined orientation crack (AB) is assumed variable. The orientation of the inter notch-cracks $(A B)$ and $(C D)$ varies; In this case the two cracks sizes are assumed invariable.

\section{Case (1):}

The objective of this investigation is an analysis of the effect of the distance L separating two cracks AB and CD. The two cracks are considered constant in size and have the same length; the crack CD at notch is parallel to crack AB and located near it as shown in Fig. 8.a.

The Fig. 9 represents the variations of the J-integral at the crack tip D of the crack CD with respect to the distance L. it can be observed that the J-integral at crack tip becomes greater with the transversal distance. It has a maximum value at $\mathrm{L}=24 \mathrm{~mm}$ after which it stabilizer and the interaction effect of these cracks disappears completely.

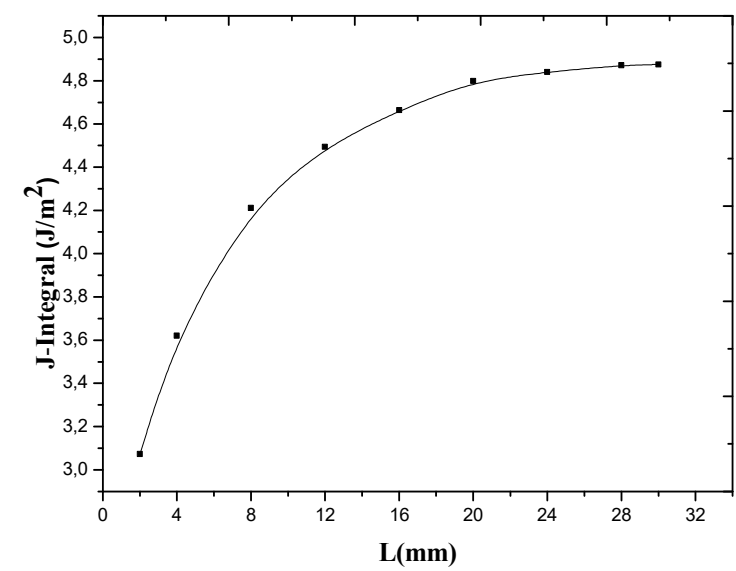

Figure 9: Variation of the J-integral at crack tip D versus distance L.

The behavior is proved by results shown in Fig.10 representing the variation of the J-integral at tips A and B of the crack AB. The J-integral becomes smaller at tip A when it gets away from the CD crack and stabilized for a distance L $>24$ mm after which the J-integral becomes independent for a distance L less than $24 \mathrm{~mm}$, the J-integral value has an exponential evolution with decreasing distance L. It is observed that the J-integral value at tip A is greater than at Tip B. The effect of interaction vanishes when the distance between the cracks approaches $24 \mathrm{~mm}$ at which J-integral values at tip A and B are similar.

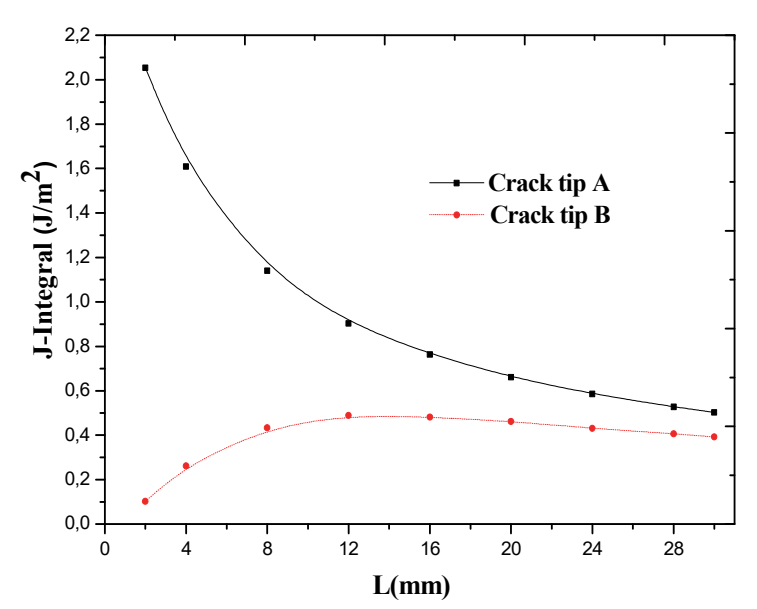

Figure 10: Variation of the J-integral at crack tip Crack tip A and B versus distance L. 
Case (2):

In the following part, the $\mathrm{AB}$ crack is moved transversally near the notch of the crack CD see in Fig.8.b.This displacement has an effect on the J-integral as presented in Fig. 11.

It is observed it value at tip $D$ is maximum when the transversal distance $d=8 \mathrm{~mm}$ and the minimum value when $\mathrm{d}=0$ $\mathrm{mm}$; when $\mathrm{d}>0 \mathrm{~mm}$ or $\mathrm{d}<8 \mathrm{~mm}$ the effect of interaction vanishes completely and the J-integral at tips of CD crack is stabilized and becomes independent.

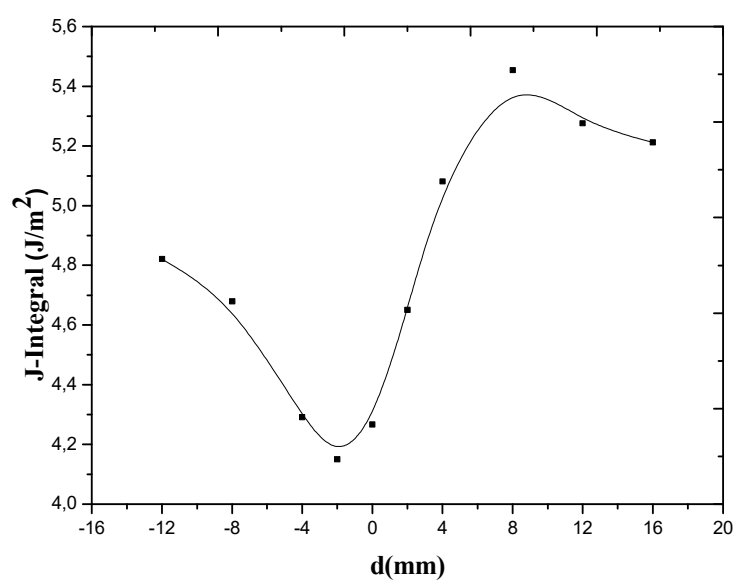

Figure 11: Variation of the J-integral at crack tip D versus distance d.

The effect of transversal distance is also investigated for AB crack tips. This is illustrated in fig 12. From this figure the maximum J-integral values at tips $\mathrm{A}$ and $\mathrm{B}$ are attained when $\mathrm{d}$ tends to $2 \mathrm{~mm}$.

The minimum is obtained for $\mathrm{d}=-12 \mathrm{~mm}$ and $\mathrm{d}=16 \mathrm{~mm}$ at which the effect of interaction vanishes. Form Fig. 11 we can see that the J-integral is critical at $\mathrm{d}=2 \mathrm{~mm}$ where the effect is significant.

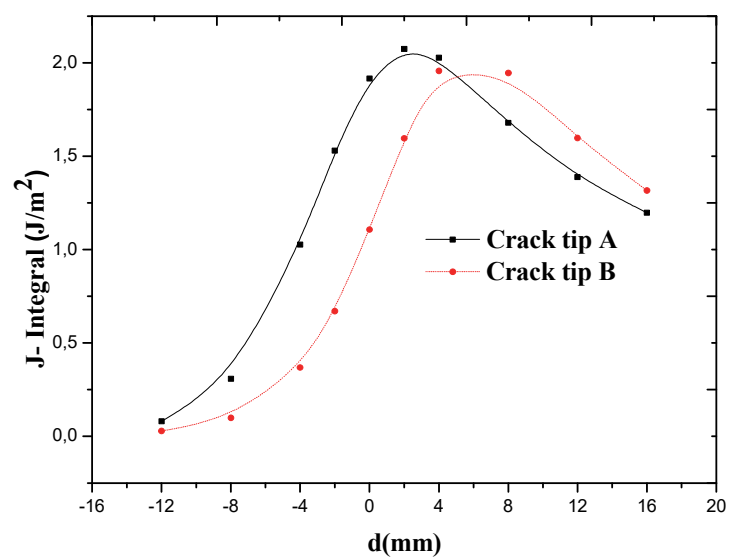

Figure 12: Variation of the J-integral at crack tip A and B versus distance d.

Case (3):

From the preceding studies treating the effect due the longitudinal displacement represented in Fig.8.c, the obtained results represented in Fig.13.

The figure shows the J-integral variations with respect to the distance d between the crack tips. It is noticed the interaction effect is dependent on the distance $d$.

When crack tip B approaches crack tip D. The J-integral at crack tip D increases exponentially.

It is also observed a critical distance at $\mathrm{d}=16 \mathrm{~mm}$ after which the J-integral is not stable. The interaction effect disappears completely. The effect of these cracks is determinant when they are closer to each other. 
Since crack tip B lies in the direction of propagation of the CD crack the J-integral value is grater at tip A than at tip B. For a distance $\mathrm{d}>12 \mathrm{~mm}$ the values of $\mathrm{J}$-integral at tip $\mathrm{A}$ and $\mathrm{B}$ are similar.

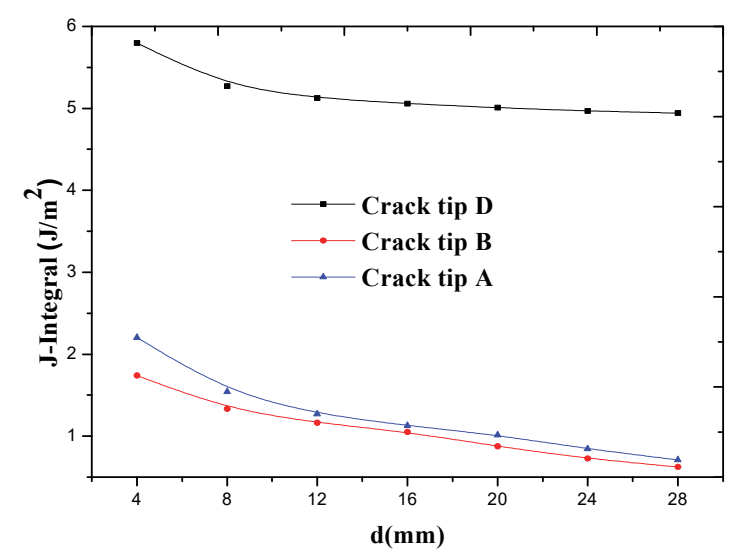

Figure 13: Variation of the J-integral at crack tip versus distance d.

\section{Case (4):}

In the following subsection, the orientation of crack $\mathrm{AB}$ is varied near the crack notch $\mathrm{CD}$ as shown in Fig.8.d The effect of the orientation of the crack $\mathrm{AB}$ on the J-integral at crack tip $\mathrm{D}$ is represented in Fig.14. It can be observed the J-integral is maximum when the crack $\mathrm{AB}$ is parallel to the loading to a low stress and strain fields at it tips. Regarding the effect of orientation of the $\mathrm{AB}$ crack on the J-integral variations at tips $\mathrm{A}$ and $\mathrm{B}$, the results show that the maximum is observed for a parallel orientation i.e (angle $\theta=0^{\circ}$ and angle $\theta=180^{\circ}$ ) with respect to the $\mathrm{CD}$ crack notch.

For these positions, the $\mathrm{AB}$ crack is an opening mode and its tips are closer to the $\mathrm{CD}$ crack tip. The minimum of $\mathrm{J}$ integral is reached for angle $\left(\theta=90^{\circ}\right)$ orientation to the $\mathrm{AB}$ crack. In this position the load is parallel to the $\mathrm{AB}$ crack and its tips $\mathrm{A}$ and $\mathrm{B}$ are practically notch under stress and strain fields.

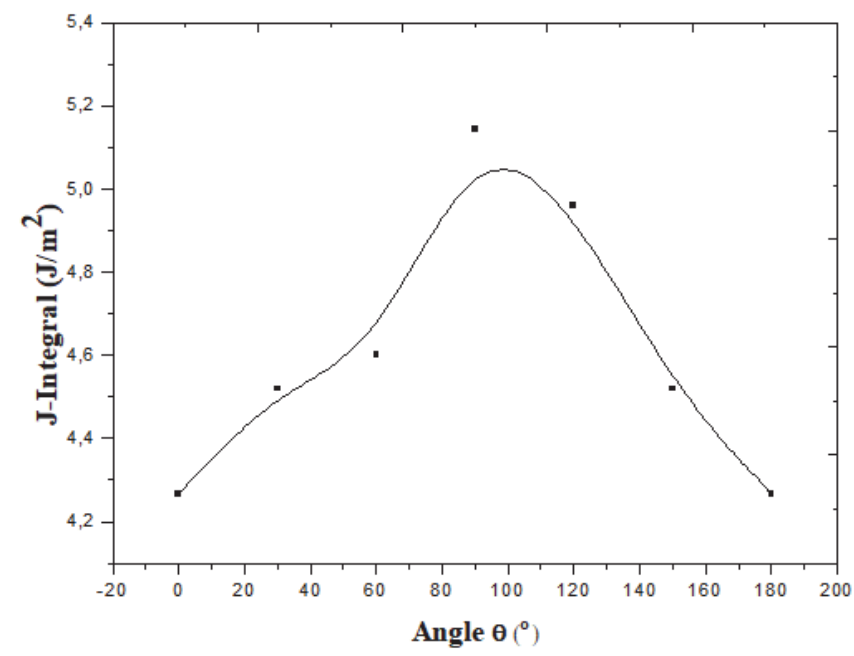

Figure 14: Variation of the $\mathrm{J}$ integral at crack tip $\mathrm{D}$ versus angle $\theta$.

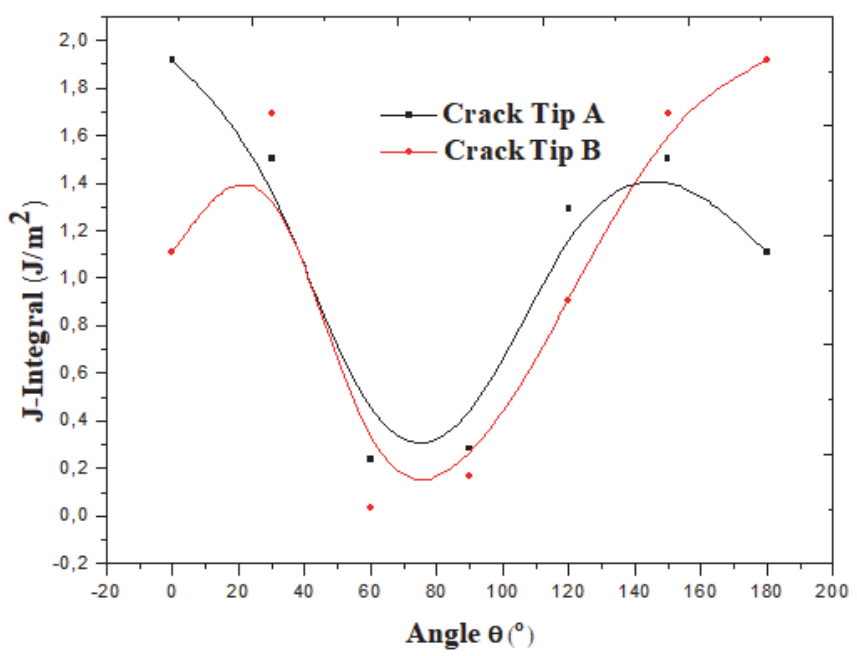

Figure 15: Variation of the $\mathrm{J}$ integral at crack tip $\mathrm{A}$ and $\mathrm{B}$ versus angle $\theta$.

\section{Case (5):}

In order to analyze their effects on the J-integral at the tip of notch cracks in FGM plate, let us consider the same structure, the orientation between the cracks at notch is varied. The length of notch cracks has same length (Fig.8.e). The Fig.16 represents the variation of the J-integral in mode I as a function of the variation of the inclination angle between the crack $\mathrm{AB}$ and $\mathrm{CD}$ at notch. 
It is noted that the J-integral is the same for $\theta=0$ between to two cracks (when the two cracks is parallel to loading). As $\theta$ increases, the J-integral at crack tip A increases asymptotically and it decreases at crack tip D. at crack tip A the resistance to the crack propagation increases as $\theta$ increases and inversely this resistance increases at crack tip D (when the two cracks is perpendicular between them).

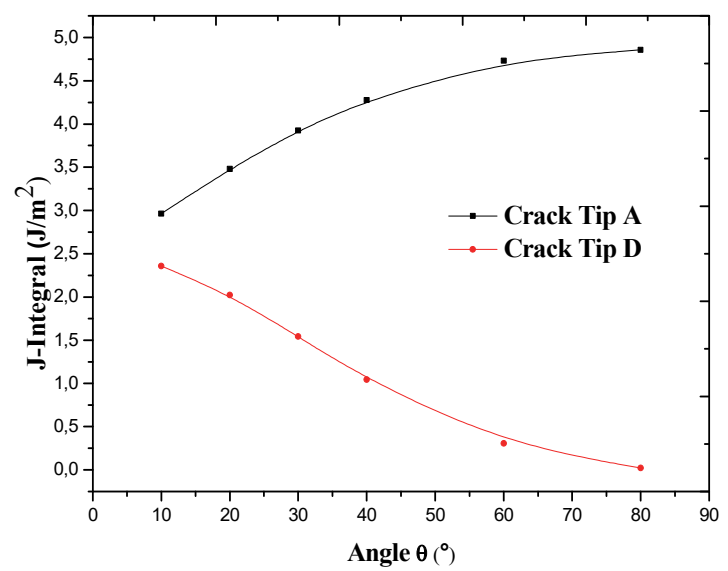

Figure 16: Variation of the J-integral at crack tip A and D versus angle $\theta$.

Interaction between two cracks with the same orientation and different size crack (c/co) on the J-integral

For two-crack interactions, the J-integral of each crack is evaluated through varying the crack length ratio for the same angle inclination. First, the ratio of the 2 nd crack length to the 1 st crack length $\left(\mathrm{c} / \mathrm{c}_{0}\right)$ ranges from 0.2 to 1.5 (Fig.8.e).

Figs. 17 and .18 describes the evolution of J-integral in different ratios of crack lengths size $\left(\mathrm{c} / \mathrm{c}_{0}\right)$ emanating from notch at angle $\theta$. It is the fact that the J-integral exhibit an asymptotic behavior as the crack length increases whatever the position of the crack in the FGM plate.

It can be noted that the J-integral at crack tip A increases with the crack length. An opposite behavior is observed for the J-integral at crack tip D. When two-crack lengths are almost similar (e.g., c/ $\mathrm{c}_{0}=1.5$ ), the magnitude of J-integral is similar. The result shows also, that the interaction vanishes with higher angle $\left(\theta=80^{\circ}\right)$, At this point the value of $\mathrm{J}$ is maximum for crack $A$ and inverse at angle $\left(\theta=20^{\circ}\right)$. The size ratio affects the value of $J$ proportionally at crack $A$, and inversely at crack D. On the other hand, the difference in the J-integral becomes increasingly important with decreasing crack length and increasing in crack inclination.

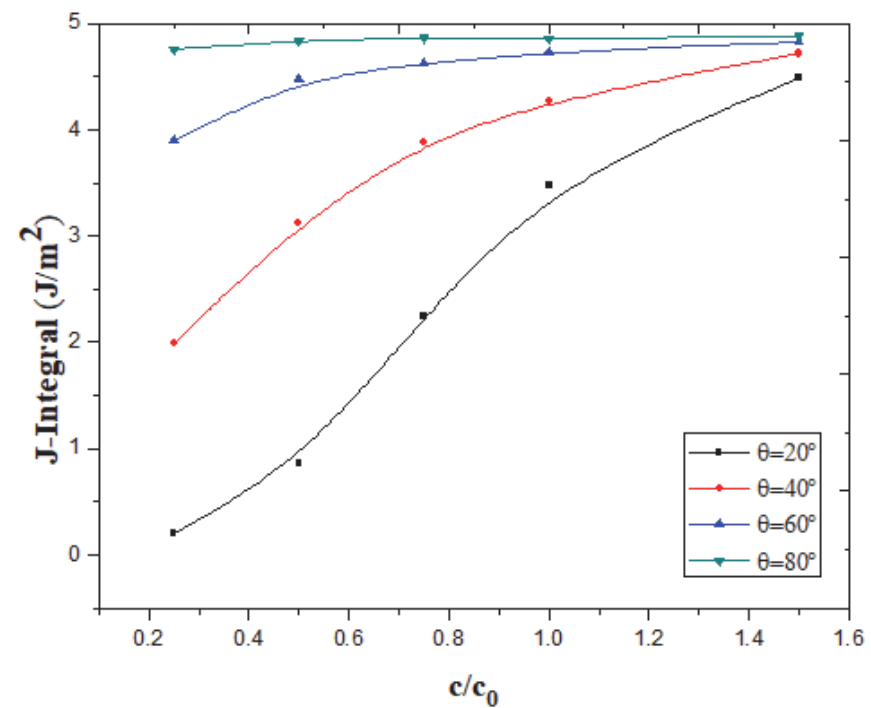

Figure 17: Variation of the J-integral at crack tip A versus $\mathrm{c} / \mathrm{c}_{0}$ crack length ratio for different changing orientation $\theta$.

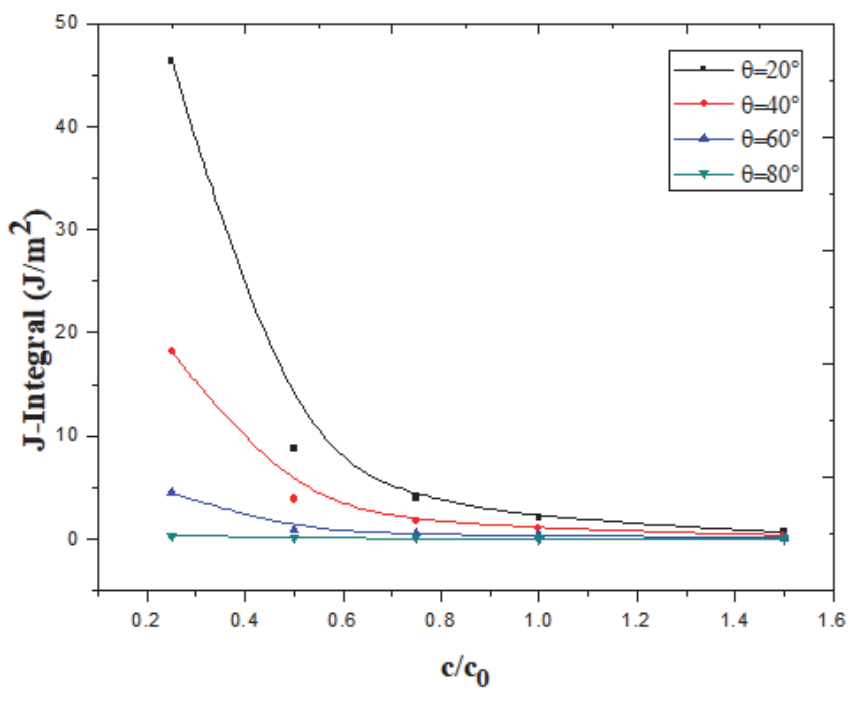

Figure 18: Variation of the J-integral at crack tip D versus $\mathrm{c} / \mathrm{c}_{0}$ crack length ratio for different changing orientation $\theta$. 
Thus, the maximum reduction of the J-integral is obtained when the cracks are parallel to the applied load direction. It can be said that the importance of J-integral reduction is strongly dependent on crack size. The larger the crack length, the relatively more important the reduction is. This is explained by the fact that the small cracks are requested in the stress field generated by the semicircular notch. The reduction in the J-integral influences directly the kinetics of the crack.

\section{Effect of notch radius and material gradient $\beta$ on J-integral}

The maximum stress is localized in the notch root which allows to characterize the notch by a J-integral that depends only of the notch geometry. Fig. 19 presents the as a function of the normalized radius (R/w) ratio of the lateral semicircular notches. It can be observed also that the J-integral becomes larger by increasing the control Radius. When the notches' normalized radius lies between 0.1 and 0.3 , the J-integral lies between 5 and $24 \mathrm{~J} / \mathrm{m}^{2}$ for circular notches for semicircular notches.

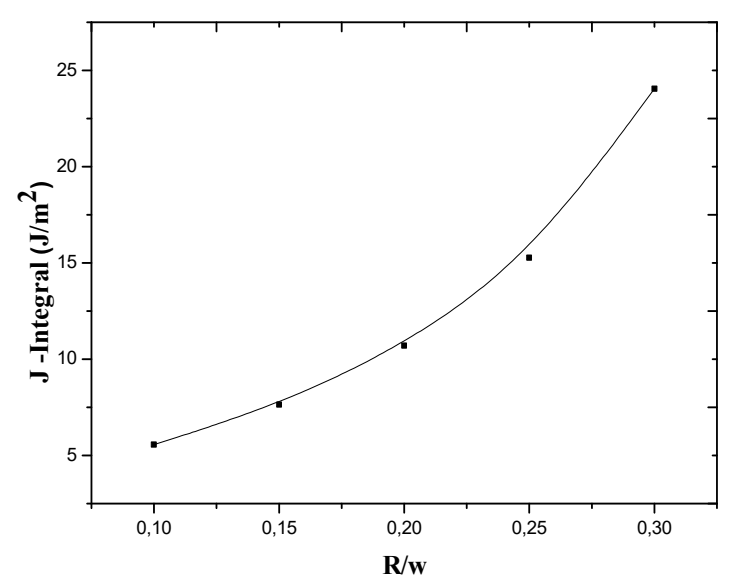

Figure 19: Variation of the J-integral versus normalized $\mathrm{R} / \mathrm{w}$ ratio with $(\mathrm{c} / \mathrm{w}=0.1, \mathrm{c} 0 / \mathrm{w}=0.1)$

The Young's modulus may vary exponentially through the FGM plate width. In this case, for example, the Young's modulus varies from 70 to $140 \mathrm{GPa}$. The Poisson's ratio assumed to be constant and equal to 0.3 . The variation of the Jintegral versus values of $\beta$ is plotted in Fig. 20.

It should be noted again that $\beta=0$ may represent the homogenous material.

For high material gradient (the exponent $\beta$ ) the J-integral is negligible, it may be concluded that the material gradient (the exponent $\beta$ ) has larger effect on the J-integral (Fig.20).

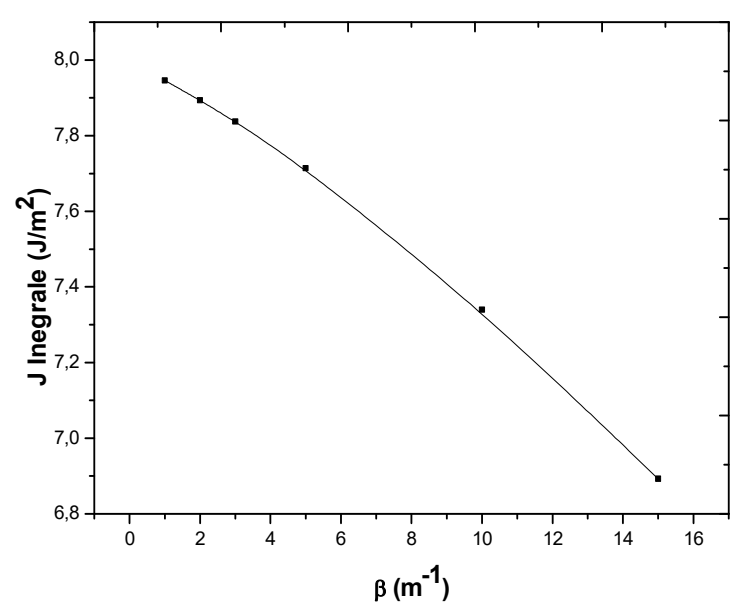

Figure 20: Variation of J-integral versus material gradient $\beta(\mathrm{c} / \mathrm{w}=0.1, \mathrm{c} 0 / \mathrm{w}=0.1)$. 
Behavior of a fixed and oblique cracks emanating from double notched FGM plate under tension

Effect of interaction of the orientation between two inter notch-cracks with equal lengths emanating from each semicircular notch root in double notched plate are studied in this part; In Fig. 21, one considers the geometrical model of the FGM plate, to ensure the opening of cracks, we let the plate be under constant unidirectional loadings $\sigma_{-} 0$ at the farfield. The influence of the orientation of the second crack $A B$ is highlighted while maintaining the angle of the first crack $\mathrm{CD}$ constant (Crack $\mathrm{CD}$ is fixed, whereas the orientation of crack $\mathrm{AB}$ is changed.).

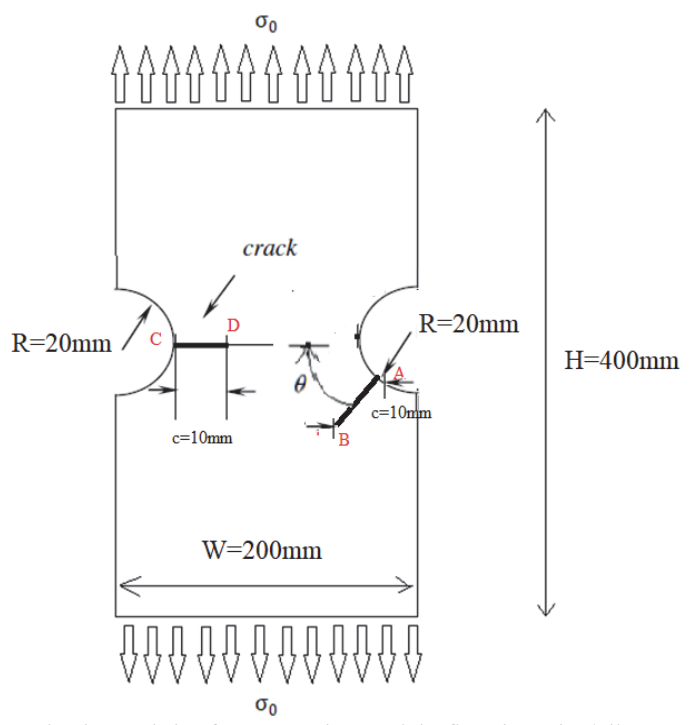

Figure 21: Geometrical model of FGM plate with fixed and oblique crack at notches.

The Fig.22 illustrates the variation of the J-integral at crack tip B and D in mode I as a function of the variation of the inclination angle of the crack $\mathrm{AB}$ at semicircular notch root. One shows respectively the effect of the main crack $\mathrm{AB}$ rotation located at notch with the angle for various values between $60^{\circ}$ and $-60^{\circ}$. Because of symmetry, the J-integral possesses the same curve for the positive and negative angles of inclination; this shows that it in independent of the sense of orientation of the existing crack $\mathrm{AB}$. In the case of the negative angles, the J-integral takes positive values and the curve is asymmetric with regard to the y-axis.

The results show also that the crack the rotation of the crack $A B$ has relatively great effect on J-integral when the crack angle is relatively small. For this case that the crack inclined angle is smaller, the traction on the crack is larger and the stresses near the crack are larger. So the crack $\mathrm{AB}$ has greater effect on the crack $\mathrm{CD}$ in the case.

Fig. 22 shows that the effect of right cracks on crack tip $\mathrm{D}$ is illustrate in this case The J-integral for both crack tips are identical as $(\theta=0)$ because of the symmetry. At this angle, the value of J-Integral is maximum. The angle of crack tip B is inversely influenced at crack tip $\mathrm{D}$. The J integral of crack tip $\mathrm{D}$ is minimum when $\theta$ increases.

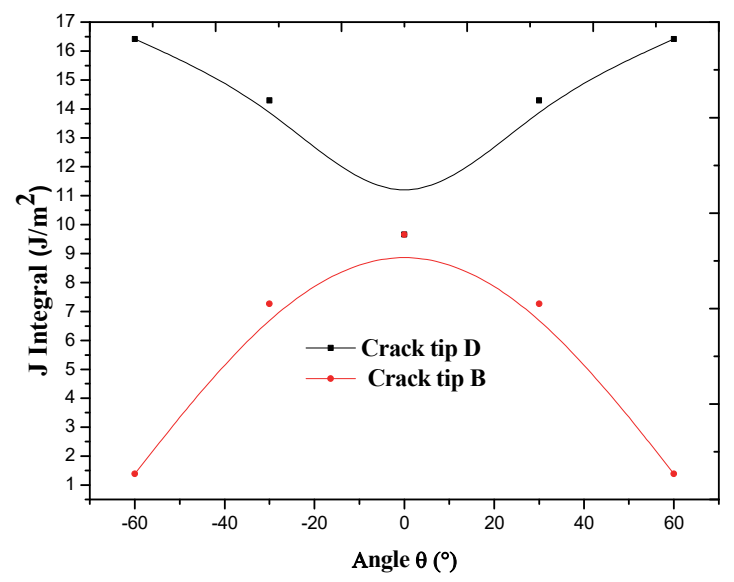

Figure 22: Variation of $\mathrm{J}$ integral at crack tips versus angle inclination $\theta$ oblique crack at crack tip B and D. 
Behavior of two oblique cracks with same angle inclination emanating from double notched FGM plate under tension

In this part the interaction of two cracks emanating from notches in a plate is investigated. As Fig. 23 indicates, we present the geometrical model of the double notched plate in the presence of two cracks located at each notch emanating from the notch root. The plate considered is subjected to the same boundary conditions.

Fig. 23 (a) shows the FGM plate geometry, Fig. 23 (a) shows the complete mesh configuration, Fig. 23 (b) shows mesh detail of two cracks and Fig. 23 (c) shows a zoom of the left crack tip region showing mesh.

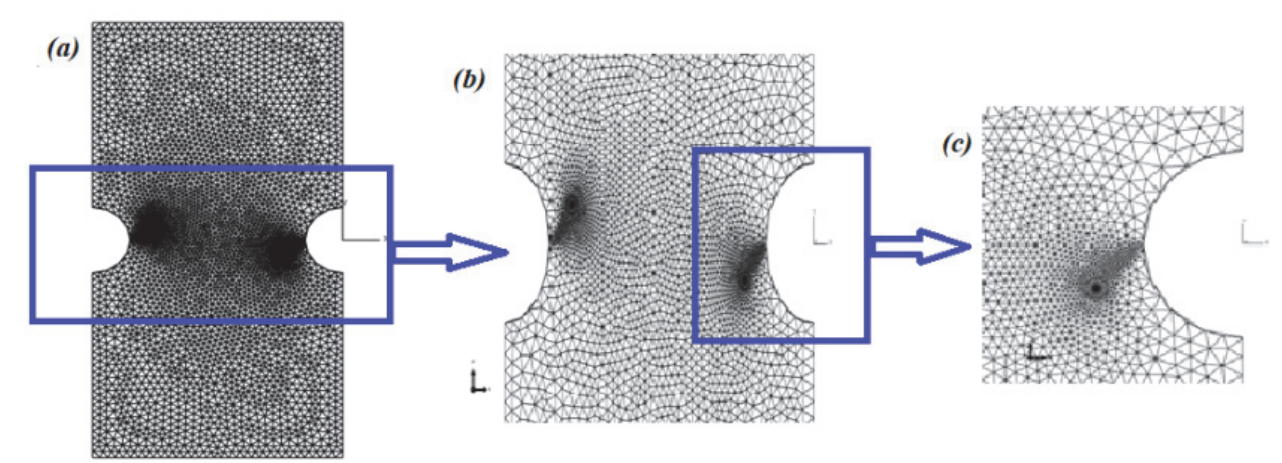

Figure 23: FGM plate with two cracks emanating from notches:(a) Geometry and complete finite element mesh; (b) mesh details of two crack tips; (c) zoom of the right crack tip

For two-crack interactions, the J-integral of each crack is evaluated through varying the crack angle inclination which is the same of the two cracks for the same length ratio.

The Fig. 24 shows the variation of the J-integral as a function of the variation of the inclination angle of the two crack. The results are respectively obtained for seven positions of the two cracks emanating from the semicircular notch with which have the same angle rotation between $\left(\theta=-60^{\circ}\right.$ and $\left.60^{\circ}\right)$. The angle is positive following the application of the principle of local symmetry. It is clear that the J-integral curves are symmetric with regard to the ligament of the plate. The curves take the importance when the angle $\theta$ decreases. One notices that function J-integral $(\theta)$ passes by a maximum corresponding to the angle $\theta=0$ of the two existing cracks (i.e. the preexisting cracks is perpendicularly oriented with respect the applied load).

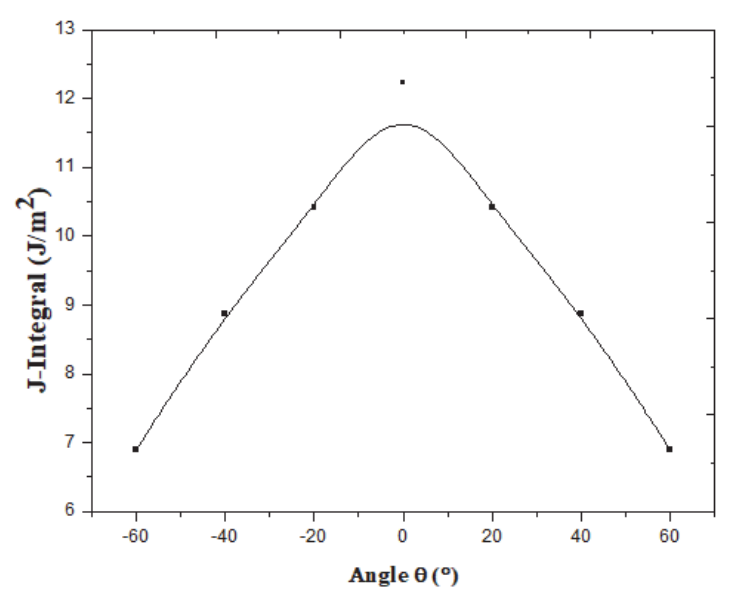

Figure 24: Variation of J-Integral versus angle inclination $\theta$ of two cracks.

\section{NEW TECHNIQUES TO REDUCE THE J-INTEGRAL WITH FGM MATERIALS}

\section{Effect of FGMs layers jointed on ceramic plate (TiB) to reduce the J-integral}

$\checkmark$ he real structures are of complex geometrical forms containing numerous zones of stress concentrations. These sites are characterized by weak sections due to the presence of notches which are the main causes of cracks initiation. The knowledge of the distribution of the stress field in the neighborhood of a notch is of an extreme 
importance for the analysis of the variation of the J-integral.

This section has been made to determine the performance of the (Ti-TiB) FGM materials to reduce the J-integral calculated for the crack tip emanating from the semicircular notch root in mode I, when the crack is propagated from the notch root. Two-crack interactions in a double notched FGM plate are investigated with remote tension $\left(\sigma_{0}\right)$. The geometry of a notched plate with two cracks is shown in Fig. 25. For two cracks of AB and CD, the lengths of two cracks are $\mathrm{c}$ and $\mathrm{c}_{0}$.

In order to analyze the effect of a FGM layer jointed on ceramic plate (TiB) for reducing the integral J on the repair of the cracks emanating from the notch subjected to unidirectional tensile load was studied (Fig. 25.c), we consider the geometric model of a TiB ceramic plate containing two FGM layers $\left(\mathrm{R}_{1}-\mathrm{FGM}\right.$, (Ti-TiB)) around a circular notch of radius $\mathrm{R}$, the layer is of width $\mathrm{w}_{0}\left(\mathrm{w}_{0}=\mathrm{R}_{1}-\mathrm{R}\right)$ as shown in Fig. (25.b).
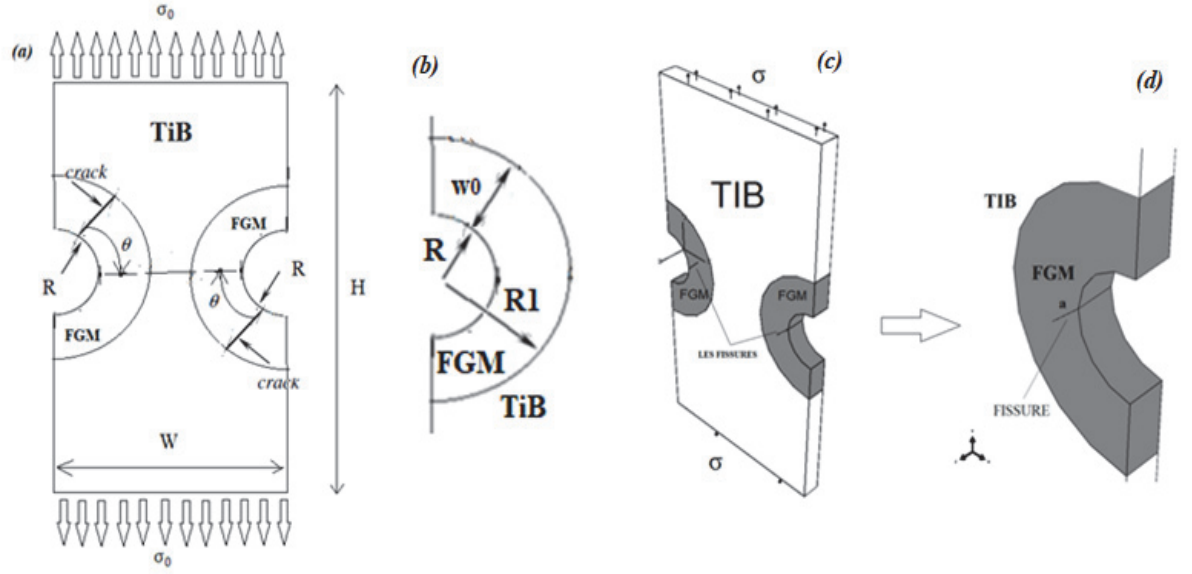

Figure 25: Geometric model of a ceramic plate (TiB) jointed with two FGMs layers at notches.

For a better illustration of the beneficial effect of the FGM materials to reduce the J-Integral, it is plotted in Fig. 26 , the variation of the asymptotic J-Integral according to the FGM layer $\mathrm{w}_{0}$ defined as $\mathrm{w}_{0}=\mathrm{R}_{1}-\mathrm{R}$ for a double notched jointed to TiB plate for various load applied.

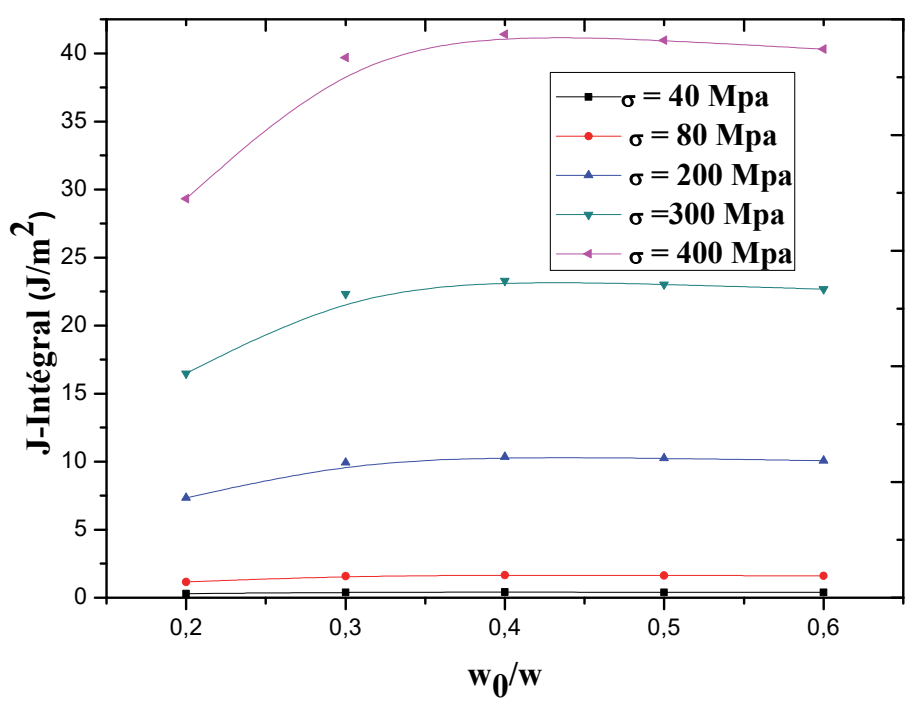

Figure 26: Variation of the $\mathrm{J}$ integral versus $(\mathrm{w} 0 / \mathrm{w})$ ratio. $\left(\mathrm{c} / \mathrm{w}=\mathrm{c} 0 / \mathrm{w}=0.1, \theta=45^{\circ}\right)$. 
On one hand, The J-integral is affected by the FGM layer jointed. The increase in the width leads to the increase in the Jintegral. The J-integral is stabilized when FGM layer jointed width exceeds $\mathrm{w}_{0} / \mathrm{w}=0.4$. This effect is due to the fact that the increase in the size of the FGM layer jointed width involves an increase in the stress field at the crack tip, which leads to a saturation of the stresses transfer. This saturation involves a stabilization of the increase of the $\mathrm{J}$ integral according to the crack size, an optimization of the FGM layer width is recommended. On the other hand, the J-integral increases proportionally with the increment in the applied loads.

The use of a FGM layer of size $\mathrm{w}_{0} / \mathrm{w}=0.2$ results in a significant decrease of the J-Integral with a gain of $(69 \%)$. The maximum of $\mathrm{J}$ is almost at the level of $\mathrm{w}_{0} / \mathrm{w}=0.4$ with gain of $(52 \%)$.

\section{Effect of the radius of notched FGM layer for reduce J-integral}

The influence of the geometry plate is very important, In order to determine the effect of the notch radius on the performance of the bonded TiB plate repair by FGM layer jointed in Mode I, The orientation of notched $\mathrm{crack}^{\text {is }} \theta=45^{\circ}$ for FGM layer width of $\mathrm{w}_{0} / \mathrm{w}=0.125$ maintained constant.

Fig. 27 presents the variation of the J-integral as a function of the notch radii for various subject loads. From It is noted that the J-integral increased such that the important factor $(\mathrm{R} / \mathrm{w})$ in FGMs layers $\mathrm{w}_{0} / \mathrm{w}=0.125$, the difference of the $\mathrm{J}$ integral becomes larger and more important with the increase of the notch radius and important load.

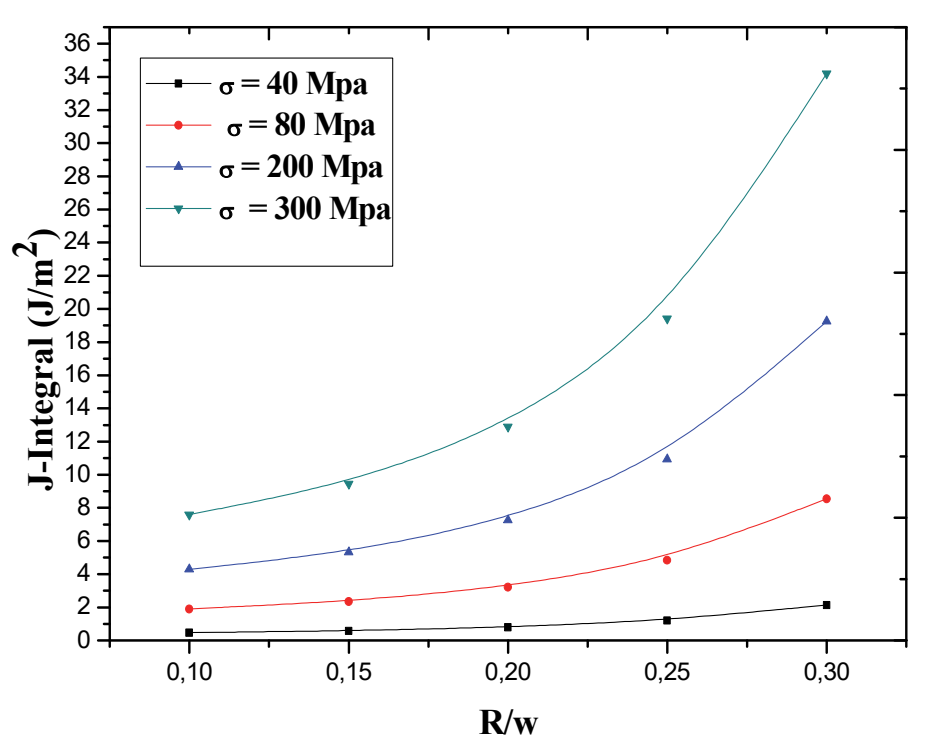

Figure 27: Variation of the J-integral versus $\mathrm{R} / \mathrm{w}\left(\mathrm{w}_{0} / \mathrm{w}=0.125, \mathrm{c} / \mathrm{w}=\mathrm{c}_{0} / \mathrm{w}=0.1, \theta=45^{\circ}\right)$

\section{CONCLUSION}

he primary goal of a designer is to predict whether a crack in a component is likely to grow under the given loading conditions. He can either obtain the critical J-integral at crack tip to determine it. The objective of this work is to describe the effect of interaction between two cracks in notched and double-notched (TiB/Ti) FGM plate. The plate is numerically simulated using the finite element method (FEM).

The obtained results allow us to deduce the following conclusions:

- The transversal $(L)$ and longitudinal $(d)$ displacement and the angle of orientation $(\theta)$ characterizing the interaction effect between two cracks plays an important role on the level and distribution of J-Integral.

- For the transversal displacement $(L)$ and longitudinal $(d)$; The J-Integral increases dramatically and reaches its maximum value. For a far displacement, the interaction effect disappears completely; it results in a stabilization of the J-Integral at a constant value.

- The effect of between two cracks interaction depends not only on their interdistance but also the orientation angle of between these two cracks. The $\mathrm{J}$ integral reaches its maximum when the crack is directly parallel to the 
load. This orientation leads to the crack opening. A perpendicular orientation causes the closing of the crack leading to negligible J-integral.

- A normal crack to load leads to a highest J-Integral at the crack tip. This energy decreases gradually as the orientation angle decreases.

- The J-integral at the crack tip depend both on the crack length and its position,

- The increase of the crack length causes an increase in the J-integral. The crack propagation leads to an increase of fracture energy.

- In case of two cracks emanating from notch in a FGM plate under tension, the interaction and their effect on the $\mathrm{J}$-integral is important when value of $\theta$ is maximum

- Effect of the orientation with different crack sizes is remarkable ; the maximum of J-integral is obtained when the angle increases corresponding obtained when the crack is parallel to loading and higher size, and the minimum value is obtained for the crack perpendicular to loading.

- For the case of two cracks emanating from double notched FGM plate under tension, the J integral for both crack tips are identical as $(\theta=0)$ due to symmetry. At this angle, the J-Integral value is maximum. The angle of crack $B$ is inversely influenced at crack $A$. The $J$ integral of crack $A$ is minimum when $\theta$ increases.

- The effect of the loading and the notch radius ratio $(\sigma 0, \mathrm{R} / \mathrm{w})$ on the J-integral was highlighted; the interaction grows for high value of the loading and notch radius.

- The good choice of the FGMs layers at the notches in ceramic plate (TiB) and notch radius must be optimized; because it is the best means for decreasing the J-integral considerably and improves the fracture strength.

- The decrease of the J-integral becomes more and more important with the importance of the semicircular FGM Layer radius around the notch. The use of a FGM layer of size $\mathrm{w}_{0} / \mathrm{w}=0.2$ results in a significant decrease of the $\mathrm{J}$ Integral with a gain of $(69 \%)$. The maximum of $\mathrm{J}$ is almost at the level of $\mathrm{w}_{0} / \mathrm{w}=0.4$ with gain of $(52 \%)$.

These results are helpful to analyze the fracture or fatigue behaviors of the materials.

\section{REFERENCES}

[1] Matsumto, T.,Tanaka, M. and Obara, R. (2000). Computation of stress intensity factors of interface cracks based on interaction energy release rates and BEM sensitivity analysis, Eng. Fract. Mech., 65(6), pp. 683-702.

DOI: 10.1016/S0013-7944(00)00005-9.

[2] Hammond, M., and Fawaz, S. (2016). Stress intensity factors of various size single edge-cracked tension specimens: A review and new solutions, Eng. Fract. Mech. 153, pp. 25-34. DOI: 10.1016/j.engfracmech.2015.12.022.

[3] Ismail, A.E., Azlan, MA., Mohd Tobi, AL. , Ahmad, MH. (2016). Mode I stress intensity factors of slanted cracks in plates IOP Conf. Series: Mat. Sci. and Eng. 152, pp. 012-049.

[4] Yan, X., Miao. C. (2012). Interaction of multiple cracks in a rectangular plate. Appl. Math. Mod. 36, pp. 5727-5740. DOI: 10.1016/j.apm.2011.12.060.

[5] Yang, C.H. and Soh, A.K. (2002), Modeling of voids/cracks and their interactions. Theo. and Appl. Frac. Mech., 38, pp.81-101. DOI: 10.1016/S0167-8442(02)00083-6.

[6] Shu, H. M. Petit, J. Jiang, Z. D. and Bezine, G. (1993). Stress intensity factors and interaction of three cracks on both edges of finite width sheet, Eng. Frac. Mech., 45(3), pp. 407-414. DOI: 10.1016/0013-7944(93)90026-O.

[7] Ismail, A.E. (2013). Stress intensity factors of three parallel edge cracks under bending moments. IOP Conf. Series: Mat. Sci. and Eng. 50, pp. 12-20.

[8] Ismail, A.E. Ariffin, A. Abdullah, K .Ghazali, M.J. (2013). Stress intensity factors under mode III loadings. Inter. Rev. of Mech. Eng. 7(3), pp. 578-582.

[9] Chen, L. S. Kuang, J. H. (1992). A Displacement Extrapolation Method for Determining the Stress Intensity Factors along Flaw Border, Inter. Jour. of Frac., 57 (4), pp. R51-R58. DOI: 10.1007/BF00013064.

[10] Albinmousa, J. Merah, N. and Khan, SMA. (2011). A model for calculating geometrical factors for a mixed-mode III single edge notched tension specimen .Eng. Frac. Mech. 78, pp. 3300-3307.

DOI: $10.1016 /$ j.engfracmech.2011.09.005.

[11] Ismail, A.E. (2013). Development of J-integral prediction model for surface cracks in rounds bars under combined loadings. Appl. Mech. and Mat. 315, pp. 665-669. DOI: 10.4028/www.scientific.net/AMM.315.665. 
[12] Murakami, Y. (1987). Stress Intensity Factors Handbook Volume 1, Pergamon Press. Stress intensity factors handbook. (1990) Vol.1, Ed Y. Murakami, Pergamon Press. Murakami, Y. (1986) Two semi-infinite solids bonded by a bond of arbitrary shape subjected to tensile load. In: Stress intensity factor handbook. Japan: Soc. of Mat. Sci. DOI: $10.1115 / 1.2900983$.

[13] Ismail, A.E. Ariffin, A.K. Abdullah, S. Ghazali. M.J (2014). J-integral evaluation of surface cracks in round bar under mode III loadings. Research Journal of Applied Sciences, Engineering and Technology 7 (10) 1985-1993. DOI:10.19026/rjaset.7.490.

[14] Honein, T. and Herrmann, G., (1997). Conservation laws in nonhomogeneous plane elastostatics, Journal of the Mech. and Phy. of Sol., 45( 5), pp. 789- 805. DOI: 10.1016/S0022-5096(96)00087-7.

[15] Jin, Z. H. and Batra, R., (1996).Some basic fracture mechanics concepts in functionally graded materials, Journal of the Mechanics and Physics of Solids, 44(8), pp. 1221-1235.

[16] Li, F. Z., Shih, C. F. and Needleman, A., (1985). A comparison of methods for calculating energy release rates, Engineering Fracture Mechanics, 21(2), pp. 405-421. DOI: 10.1016/0013-7944(85)90029-3.

[17] Ismail, A.E, Mohd Tobi, AL. and Mohd Nor, N.H. (2015) Stress intensity factors of slanted cracks in round bars subjected to mode I tension loading AIP Conference Proceedings 1660070027.

[18] Bouida, N. Bouchikhi, A.S. Megueni, A. and Gouasmi, S. (2018). A Finite Element Analysis for Evaluation of JIntegral in Plates Made of Functionally Graded Materials with a Semicircular Notch. J Fail. Anal. and Preven. 18, pp. 15-33. DOI: 10.1007/s11668-018-0558-6.

[19] ABAQUS Finite Element Program. (2008) ABAQUS/Standard 6.9.1. Hibbit, Karlsson and Sorensen, Inc. Pawtuket, USA.

[20] Freese, C.E., Tracey, D.M . (1976). The natural triangle versus collapsed quadrilateral for elastic crack analysis. Int. J. of Fract. 12, pp. 767-770. DOI: 10.1007/BF00037924.

[21] Barsoum, R. S. (1976). On the use of isoparametric finite elements in linear fracture mechanics. Int. J. for Num. Meth. in Eng., 10, pp. 25-37. DOI: 10.1002/nme.1620100103

[22] Xie, M., Gerstle, W.H., Rahulkumar, P. (1995). Energy-based automatic mixed-mode crack-propagation modeling. J. of Eng. Mech. ASCE. 121, pp. 914-923. DOI: 10.1061/(ASCE)0733-9399(1995)121:8(914).

[23] Bittencourt, T. Wawrzynek, P.A., Ingraffea, A.R., Sousa, J.L. (1996). Quasi-automatic simulation of crack propagation for 2D LEFM problems, Eng. Fract. Mech., 55, pp. 321-334.

[24] Chiou, Y.J., Lee, Y.M., Jowtsay, R. (2002). Mixed mode fracture propagation by manifold method. Int. J. of Fract. 114, pp. 327-347.

[25] Guan, Z.Q., Song, C., Gu, Y.X. (2003). Recent advances of research on finite element mesh generation methods. J. of Comp. Aided Design and Comp. Graph. 15 (1), pp. 1-14. DOI: 10.1023/A:1015713428989

[26] Zienkiewicz, O., Taylor, R., Zhu, J. Elsevier Ed.(2005).The finite element method: its basis and fundamentals. Sixth Publisher.

[27] Muthu, N. Maiti, S.K. Falzon, B.G. Guiamatsia, I. (2013). A comparison of stress intensity 28 factors through crack closure integral and other approaches using eXtended element-free Galerkin method. Computational Mechanics, 52, pp. 587-605. DOI: 10.1007/s00466-013-0834-y.

[28] Muthu, N. Maiti, S.K. Falzon, B.G. Khoddam, S. (2014). Modified crack closure integral for extraction of SIFs in meshfree methods. Finite Element in Analysis and Design, 78, pp. 25-39. DOI: 10.1016/j.finel.2013.09.005.

\author{
APPENDIX \\ User subroutine USDFLD FOR FGMs \\ **USER SUBROUTINE \\ SUBROUTINE USDFLD(FIELD,STATEV,PNEWDT,DIRECT,T,CELENT, \\ 1 TIME,DTIME,CMNAME,ORNAME,NFIELD,NSTATV,NOEL,NPT,LAYER, \\ 2 KSPT,KSTEP,KINC,NDI,NSHR,COORD,JMAC,JMATYP,MATLAYO,LACCFLA) \\ C INCLUDE 'ABA_PARAM.INC' \\ C CHARACTER*80 CMNAME,ORNAME \\ CHARACTER*3 FLGRAY(15) \\ DIMENSION FIELD(NFIELD),STATEV(NSTATV),DIRECT(3,3), 1 T(3,3),TIME(2) \\ DIMENSION ARRAY(15),JARRAY(15),JMAC(*),JMATYP(*),COORD $(*)$ \\ C DIMENSION INTV(1),REALV(1)
}




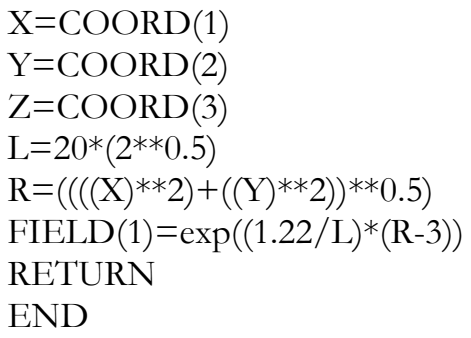

END 